\title{
Causas do desmatamento da Amazônia: uma aplicação do teste de causalidade de Granger acerca das principais fontes de desmatamento nos municípios \\ da Amazônia Legal brasileira
}

\author{
Marcelo Bentes Diniz. \\ Professor do PPGECONOMIA/UFPA \\ José Nilo de Oliveira Junior \\ Professor do PPGECONOMIA/UFPA
}

\section{Palauras-chave}

Amazônia; desmatamento; causalidade.

Classificação JEL C59, Q23.

Key words

Amazon; deforestation; causality.

JEL Classification C59, Q23.

\section{Resumo}

Muitas são os fatores, apontadas pela literatura pertinente, acerca das causas do desmatamento da Amazônia Legal brasileira. Desde aspectos endógenos como as condições edafo-climáticas, a aspectos relacionados à ação antrópica como os movimentos populacionais, o crescimento urbano e, em especial, as ações autônomas ou induzidas dos diversos agentes econômicos públicos e privados que têm atuado na região, configurando historicamente os processos de ocupação do solo e aproveitamento econômico do espaço amazônico. Este artigo tem como objetivo realizar um teste de causalidade, no sentido de Granger, nas principais variáveis sugeridas como importantes para explicar o desmatamento da Amazônia Leser empregada se baseia em modelos dinâmicos para dados em painel, desenvolvidos por HoltzEakin et al. (1988) e Arellano-Bond (1991), que desenvolveram um teste de causalidade baseado no artigo seminal de Granger (1969). Entre os principais resultados obtidos está a constatação empírica de que existe uma causalidade bidirecional entre desmatamento e as áreas de culturas permanente e temporária, bem como o tamanho do rebanho bovino. gal, no período de 1997 a 2006. A metodologia a

\author{
Nicolino Trompieri Neto \\ Instituto de Pesquisa e Estratégia Econômica \\ do Ceará - IPECE \\ Márcia Jucá Teixeira Diniz
} Professora do PPGECONOMIA/UFPA 


\section{1_Introdução}

Segundo os dados consolidados do Projeto de Monitoramento do Desflorestamento da Amazônia Legal (Prodes), ligado ao Instituto Nacional de Pesquisas Espaciais, foram desmatados, em 2007, cerca de 11,5 mil km² da Amazônia Legal brasileira. No acumulado, estimava-se que, até 2004 , aproximadamente $18 \%$ do território da Amazônia Legal teria sido alterado por algum tipo de ação antrópica (MIN e MMA, 2004).

Todavia, a diversidade interna da Amazônia, tanto em relação as suas características naturais quanto ao seu processo de ocupação, acabou por ter uma conformação de seu território, que pode ser resumida em três macrorregiões:

1. Arco do Povoamento Adensado, que corresponde aos Estados do Mato Grosso, de Rondônia e do Tocantins, e as partes do Sudeste e do Nordeste do Pará, do Sudeste do Acre e do Sul do Amapá;

2. Amazônia Central, que compreende o Oeste e o Norte do Estado do Pará, o Norte do Estado do Amapá e o Vale do Rio Madeira, no Estado do Amazonas;

3. Amazônia Ocidental, que congrega o Estado de Roraima, todo o restante do Estado do Amazo- nas e as partes Central e Oeste do Estado do Acre.

Historicamente, são os dois primeiros macroespaços que possuem uma lógica econômica baseada em vetores de desmatamento, sendo este último contrabalançado pelo efeito virtuoso que a Suframa e o Polo Industrial de Manaus têm exercido sobre o território em sua área de influência (Rivas et al., 2008).

Ressalta-se que essa conformação territorial (e ocupacional) está relacionada direta ou indiretamente aos meios de acesso à região e como esses vão servindo de canalizadores do processo migratório, do crescimento demográfico e dos adensamentos urbanos decorrentes. O Arco do Povoamento, por exemplo, está diretamente relacionado ao adensamento de estradas, com um aumento da densidade demográfica no cinturão que se formou entre $300 \mathrm{e}$ 500 quilômetros quadrados de largura para essas (Becker, 2006).

Por outro lado, o histórico do desmatamento pelos números do Ministério da Integração Nacional e do Ministério do Meio Ambiente (2004) acompanhou uma trajetória com diferentes intensidades, com pelo menos dois recortes temporais distintos, a saber: até 1980 e a partir da década de 1980.

No primeiro recorte, o desmatamento auferido está relacionado a um proces- 
1 Para uma retrospectiva desse período e seu impacto sobre o desmatamento, ver, por exemplo, Becker (1990). Ainda, segundo Becker, o período entre 1966 e 1985 marca o planejamento efetivo na região amazônica, em uma fase denominada por ela de "Produção do Espaço Estatal" (Becker, 2006). so de desbravamento induzido pelo Estado, com a abertura de estradas e os projetos de colonização oficiais. ${ }^{1} \mathrm{E}$ ainda a estruturação da atividade pecuária aproveitando certas vantagens comparativas locais e a conjunção de incentivos fiscais e especulação fundiária.

No segundo recorte, o processo de desmatamento ganha caráter espontâneo movido pela lógica da valorização econômica do território ocupado e pela maximização dos resultados privados da exploração dos recursos naturais, especialmente pelas atividades madeireira e pecuária, sendo esta última a de maior escala. Nas três últimas décadas, o desmatamento não só multiplica sua velocidade, mas também a sua espacialidade. Nesse período, a inércia do processo passa a ser basicamente impulsionada pela expansão da pecuária, especialmente de caráter extensivo.

$\mathrm{Na}$ primeira "etapa", a região totalizou 300 mil km² de perda da floresta original ( $6 \%$ do território regional), enquanto, na segunda "etapa", o processo de desmatamento apresentou números muito superiores. Na década de 1980, o desmatamento atinge cerca de $130 \mathrm{mil} \mathrm{km} \mathrm{km}^{2}$, enquanto, na década de 1990, 150 mil km², e, só nos primeiros anos do século XXI, por cerca de 120 mil km² (MIN e MMA, 2004).

A dinâmica mais recente, porém, de ocupação do solo, está ligada a um movi- mento de substituição de áreas de pastagem para a produção de grãos, em virtude dos altos preços alcançados por algumas commodities agrícolas internacionais (Brandão et al., 2005). Aqui aparecem, entre outros que tiveram um crescimento acentuado de sua área plantada, os Estados do Pará e do Mato Grosso e, mais recentemente, de Rondônia e do Tocantins.

Desta forma, dado o grande número de possíveis determinantes do processo de desmatamento na região, este artigo tem como objetivo realizar um teste de causalidade, no sentido de Granger, nas principais variáveis apontadas como importantes para explicar o referido processo, segundo a literatura pertinente. Para tanto, foram utilizados dados em nível municipal para a Amazônia Legal, no período de 1997 a 2006.

Para alcançar os objetivos acima descritos, utilizam-se modelos dinâmicos para dados em painel, desenvolvidos por HoltzEakin et al. (1988) e Arellano e Bond (1991), que desenvolveram um teste de causalidade baseado no artigo seminal de Granger (1969).

Além desta introdução, o artigo é composto de mais cinco seções. A seção 2 trata das evidências empíricas das causas do desmatamento; a seção 3 traz uma discussão sobre a causalidade entre as fontes principais de desmatamento; a seção 4 discute a metodologia do teste; a seção 5 estu- 
da as variáveis utilizadas; a seção 6 analisa os resultados empíricos e, por fim, a seção 7 traz as considerações finais.

\section{2_Os resultados empíricos acerca das causas do desmatamento}

\section{1_As evidências empíricas internacionais}

Geist e Lambin (2001), na tentativa de entender o padrão e as mudanças nas taxas de transformação ambiental em termos das forças impulsionadoras que agem globalmente, regionalmente e em nível dos tomadores locais de decisão responsáveis por essas transformações, apresentam ampla revisão bibliográfica da literatura internacional acerca dos fatores causais sugeridos como responsáveis pelo desmatamento nos mais diferentes países.

Com base em 152 estudos de casos nacionais, os autores agrupam as diferentes causas (ou forças impulsionadoras) em algumas características comuns, das quais resultam três grandes grupos:

i. causas agregadas primárias (diretas) e relacionadas, em número de três: expansão da agricultura, extração de madeira e expansão da infraestrutura; ii. forças direcionais (ou causas) subjacentes, que incluem ampla gama de categorias: fatores demográficos, econômicos, institucionais/ de política, culturais e políticosociais;

iii. um terceiro grupo de fatores bastante heterogêneos entre si, com características distintas que comporiam todos os demais fatores não incluídos nas duas classificações anteriores.

Segundo suas conclusões, entre as causas primárias mais significativas estariam a expansão da agropecuária, seja da cultura temporária, seja da cultura permanente, e a pecuária de caráter eminentemente extensivo; a extração da madeira para diversos usos e fins comerciais e a infraestrutura existente, que permite o acesso, o deslocamento e a fixação dos diferentes agentes que integram as atividades econômicas da agropecuária e de exploração florestal, especialmente de madeira. Neste último caso, a infraestrutura e a logística de transporte, bem como as diferentes modalidades de colonização, inclusive os assentamentos populacionais, serviriam como fatores de atração de contingentes populacionais e poderiam ser apontados como causas primárias.

As causas subjacentes comporiam o ambiente econômico, social, cultural e ins- 
titucional associados às atividades econômicas citadas. Assume destaque aqui todo o aparato jurídico, incluindo o direito de uso da terra (propriedade), bem como as políticas públicas direcionadas direta ou indiretamente ao espaço e as atividades envolvidas com o processo de desmatamento, onde concorrem ainda os fatores culturais que moldam de uma maneira ou de outra o comportamento dos agentes econômicos e mesmo das populações tradicionais.

Angelsen e Kaimowitz (1999), na análise dos resultados de 140 modelos econômicos acerca das causas do desmatamento nos países tropicais, sustentam a refutação de três teses importantes:

i. os modelos oferecem pouco suporte para a tese do crescimento populacional como uma das forças que explicam o desmatamento;

ii. a relação entre pobreza e desmatamento também parece ter pouca evidência empírica;

iii. a tese defendida pelo Banco Mundial de que o crescimento econômico, juntamente com a remoção das distorções de mercado, seria bom para pessoas e florestas não se mostrou verdadeira.

$\mathrm{Na}$ realidade, a liberalização econômica e a desvalorização cambial têm um efeito de aumentar os preços na agricultura e da madeira, incentivando o desmatamento.

Mais especificamente com relação ao que é chamado na literatura de "pobreza ambiental", isto é, a relação direta entre a pobreza da população e a degradação ambiental, Reardon e Vosti (1995) e Cavendish (1999) ratificam essa tese para alguns países detentores de florestas tropicais.

Vale ressaltar que, no caso da Amazônia, embora Wood e Schmink (1992) tenham acentuado que, graças à desigual distribuição de terras, os pobres são constantemente compelidos a procurar novas fronteiras e, por essa via, promover o desmatamento, isso não parece se repetir para anos mais recentes (Diniz et al., 2007).

A rigor, as evidências existentes quanto aos fatores ou causas do desmatamento na Amazônia, na ampla literatura existente sobre o assunto, apontam na mesma direção da literatura internacional, conquanto guardadas algumas especificidades do ambiente local, e a lógica da exploração econômica imposta pelos diferentes agentes econômicos na região e os diferentes espaços de ação desses agentes.

Como chama a atenção Fearnside (2007), o desmatamento toma lugar na Amazônia no contexto de uma diversa coleção de atores com uma grande diferença entre localização em termos de quem é o responsável. 


\subsection{As evidências empíricas para a Amazônia}

\subsubsection{O crescimento da pecuária}

Nos últimos trinta anos, a pecuária de corte e a atividade madeireira baseada principalmente na produção em tora, com pouca agregação de valor, foram as atividades que se mostraram com maiores vantagens competitivas para a região, dadas as condições de mercado, os custos de oportunidade de atividades alternativas, inclusive a rentabilidade a curto e médios prazos e mesmo as condições institucionais de facilidade ao acesso ao crédito e a baixa governança quanto à fragilidade do direito de propriedade, e os custos ambientais associados.

Vários são os fatores apontados pela literatura que tentam explicar o avanço da pecuária na Amazônia, em especial, no Pará e no Mato Grosso.

Piketty et al. (2004) apontam que, na Amazônia Oriental, o ambiente favorável da expansão da pecuária na região esteve assentado no tripé:

1. eficiência e adaptação do sistema forrageiro baseado na pastagem Brachiaria brizantha, vulgarmente chamado de "braquiarão". Esse tipo de forrageira, além de baixo custo, apresentaria maior resistência às pragas e eficiência no manejo, representando, portanto, um tipo de pastagem com adaptação singular às características extensivas da pecuária da região;

2. existência de financiamentos públicos, em um primeiro momento entre as décadas de 1970 e 1980, particularmente através do sistema Finam/Sudam e, a partir da década de 1990, pela disponibilidade dos recursos do Fundo Constitucional do Norte (FNO) do Basa;2

3. a experiência agropecuária do produtor na crença que essa atividade poderia quebrar o ciclo da pobreza. Aqui se apresenta a experiência familiar do produtor, não só das práticas agropecuárias, mas dos valores culturais e sociais já atrelados à exploração desse tipo de atividade econômica.

O baixo custo relativo também induziu que mesmo produtores de pequena escala promovessem a conversão de áreas utilizadas para agricultura de subsistência em pasto para criação de boi vivo, o qual era também considerado um símbolo de status na região (Serrão e Toledo, 1990), ao mesmo tempo em que possibilitava seu uso para fins especulativos.
2 A obrigatoriedade do título de propriedade para se pleitear os recursos do FNO acabou por não criar uma relação muita estreita entre os financiamentos com esse e o avanço da pecuária em algumas áreas da região. 
Anderson (1990) explica que a natureza especulativa da terra era um dos fatores que garantiam a rentabilidade do sistema da pecuária implantado na década de 1980 (Hecht et al., 1988), a despeito de sua inviabilidade econômica de curto e médio prazos ("sua aparente irracionalidade"). De fato, segundo esse autor, eram duas as motivações que garantiam a reprodução desse processo, a saber:

1. o valor da terra como investimento especulativo em épocas de inflação, que sobrecompensava a queda de seu retorno produtivo. Como resultado, a maioria do investimento regional foi direcionada para retorno (lucro) de curto prazo, que pôde ser gerado tanto pela simples retirada da cobertura florestal quanto seletivamente pela extração de seus componentes;

2. a facilidade de estabelecer a posse de largas áreas de terra, uma vez que elas já tivessem sido convertidas em pasto, especialmente importante em áreas de conflitos crônicos, legalizando, ao mesmo tempo, a expropriação fundiária e o desmatamento da floresta (Oliveira, 2005).
Além disso, a expansão da fronteira agropecuária era motivada pela facilidade ao crédito propiciada pelos incentivos fiscais, com uma correlação positiva entre crescimento econômico, "criação" de corredores de acesso à região, como as rodovias, a migração, e a especulação fundiária (Reis e Margullis, 1991; Young, 1998).

Os incentivos governamentais como causa ou estímulo ao desmatamento na Amazônia são acentuados também por Mahar (1988), reportando-se ao período até 1980. Segundo ainda esse autor, entre as décadas de 1960 e 1980, 10 milhões de hectares da Amazônia foram convertidos em pasto, valendo-se de políticas governamentais.

Ao longo do tempo, são criadas as condições favoráveis que permitem aumento do retorno do investimento na pecuária, de modo que, já na década de 1990, como mostrou Margulius (2004), a atividade pecuária de corte na Amazônia Oriental ${ }^{3}$ ou na chamada "fronteira consolidada" se mostra altamente rentável do ponto de vista privado, apresentando taxas de retorno superiores às da pecuária nas regiões tradicionais do País. A taxa de retorno da pecuária na Amazônia estrita (excluindo a venda de madeira) é consistentemente acima dos $10 \%$, e esses valores são potencialmente alcançados por pecuaristas estabelecidos e capitalizados na fronteira consolidada da Amazônia Ori- 
ental, sendo até superiores aos obtidos nas regiões tradicionais (Arima et al., 2005).

Assim mesmo, sem os incentivos (subsídios do governo), o que ocorreu a partir da interdição da Sudam, em 2002, a lucratividade da pecuária seria o fator de propulsão que alimentou a inércia do processo. Entre os fatores que contribuiriam para essa elevada rentabilidade, estariam:

a. condições geoecológicas favoráveis; em que pesem as altas temperaturas, a elevada pluviosidade e a umidade garantem boa produtividade das pastagens;

b. disponibilidade de terra barata, à qual pode ser acrescentada também a característica extensiva da criação, que exige pouca mão de obra, em geral, com baixa qualificação, e, portanto, com baixo custo para o produtor.

Nesse particular, Anderson (1990) sustenta que, até a década de 1980, a conversão da floresta em áreas de pastagem na Amazônia brasileira requeria massivos incentivos governamentais e uma custosa infraestrutura, como a construção e a manutenção de estradas. Todavia, já no final da década de 1980, os próprios pecuaristas, em áreas próximas de Paragominas (PA), por exemplo, eram capazes de construir as próprias estradas para o vizinho Estado do Maranhão, para a extração de madeira e expansão das áreas de fazenda.

Desta feita, na década de 1990, a rentabilidade da pecuária, por sua vez, é que levaria a pressão por abertura de estradas endógenas, criadas pelos próprios pecuaristas para baratear os custos de transportes. Ao mesmo tempo, o efeito das estradas exógenas (aquelas surgidas por motivos geopolíticos) tem um efeito considerável sobre o desmatamento somente a partir da mesma lógica da criação das estradas endógenas, de manter em última instância a rentabilidade do setor pecuário.

O Gráfico 1 apresenta as taxas de crescimento do rebanho abatido para os principais Estados que são centros de abate no País, no período entre 1998 e 2006, no qual pode ser observado o desempenho dos Estados da Amazônia Legal: Mato Grosso, Rondônia e Pará. Assim, percebe-se que esses Estados apresentaram taxas de crescimento acima da média nacional, com destaque para o Estado de Rondônia, que, no período mais recente desde 2002, apresenta uma trajetória de crescimento elevado, ultrapassando a taxa de $20 \%$ já a partir de 2004. 


\section{Gráfico 1_Variação anual das taxas de crescimento do rebanho abatido nos Estados de maior rebanho bovino no Brasil}

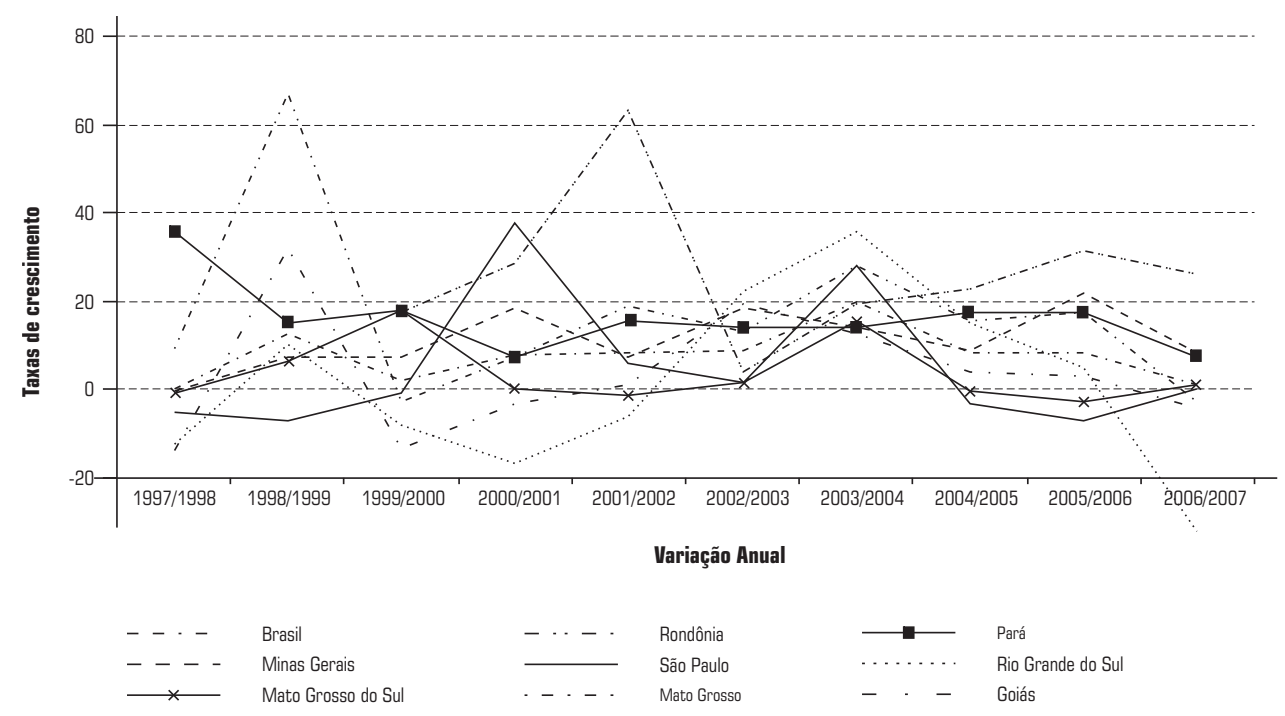

Fonte: PPM/IBGE.

Reportando-se especificamente sobre a correlação entre a provisão de infraestrutura e o crescimento demográfico, Weinhold e Reis (2001) concluem que existe mais evidência empírica para sustentar que o crescimento da população urbana leva ao desenvolvimento da infraestrutura, e não viceversa. Muito embora a relação histórica entre estradas e desmatamento é acentuada, por exemplo, em Nepstad et al. (2000 e 2001).

Por outro lado, melhoramentos urbanos como a provisão de eletricidade e de água potável teriam o papel de frear a necessidade de explorar florestas como fonte de energia e outros serviços, de modo que o melhoramento da infraestrutura urbana pode ajudar a mitigar o impacto de áreas urbanas sobre o meio ambiente, até mesmo com uma redução da população rural.

Concorrem também de modo positivo para o aumento da rentabilidade da atividade os progressos alcançados na erradicação da febre aftosa (condição indispensável para exportação da carne); os me- 
lhoramentos da saúde animal, a partir do melhoramento genético e de manejo do pasto (Arima et. al., 2005), com impactos sobre ganhos de produtividade do setor; bem como o alargamento do sistema de rastreamento animal (Nepstad et al., 2008).

Além dos efeitos diretos e indiretos das atividades pecuária e madeireira sobre o desmatamento, como destacados acima, outros fatores são sustentados por Fearnside (2007), como a lógica de desmatar para manter a possessão da área e defender o investimento contra posseiros ou da expropriação do governo (como terra devoluta); as formas de desmatamento que servem para propósito de lavagem de dinheiro, especialmente quando os fundos são derivados de fontes ilegais, como tráfico de drogas, corrupção, venda de áreas roubadas ou evasão de impostos; e a perda da cobertura vegetal "oficial" induzida pelo próprio governo, como é o caso das inundações provocadas pelas barragens hidroelétricas que no Brasil já teriam somado cerca de $10 \mathrm{mi}-$ lhões de hectares (2\% da Amazônia Legal e 3\% da porção original da floresta).

Essas variáveis, de certa forma, corroboram aquelas testadas por Andersen et al. (2002), em que os autores utilizam dados municipais, no período de 1970 a 1996, para dados do Censo Agropecuário de 1975, 1980, 1985 e 1996.

\subsubsection{0 crescimento da produção de grãos}

O crescimento da produção de grãos na região amazônica é o resultado de um conjunto de fatores que podem ser ditos internos, como, por exemplo, a adaptação de novas variedades às características climáticas da região (Fearnside, 2001), e outros externos, afetos às forças de mercado, relacionadas ao crescimento da demanda externa e ao consequente aumento de preços de algumas culturas (Nepstad et al., 2008).

O Estado do Mato Grosso acompanha a dinâmica da produção agrícola no Cerrado brasileiro, centrada na produção de grãos para exportação, a partir da década de 1980, que fez expandir a fronteira agrícola na direção do Centro-Oeste, em função de vários fatores, como os avanços tecnológicos, que possibilitaram, junto com as características edafo-climáticas da região, que se alcançasse uma produtividade física por área bastante elevada, os melhoramentos na infraestrutura de transporte e na logística de distribuição e de escoamento da produção (Diniz, 1995).

Além disso, outros fatores positivos para o crescimento especialmente da soja na região Centro-Oeste foram os baixos preços relativos da terra (comparados ao da região Sul - região tradicionalmente produtora), os incentivos financeiros ofici- 
4 Segundo Oliveira (2005), na década de 1990, o crescimento da soja no Mato Grosso teve crescimento superior a $150 \%$ na área plantada, e cerca de $225 \%$ do volume de produção. ais e as condições favoráveis de mercado (Wehrmann e Duarte, 2004).

Conquanto interferência direta de projetos e financiamentos decorrentes de ação governamentais planejadas, destacamse o Programa de Desenvolvimento do Cerrado (Proceder), de caráter federal, e o Projeto de Desenvolvimento Agroambiental de Mato Grosso (Prodeagro), desenvolvido no âmbito particular daquele Estado.

Na comparação do triênio de 1968/ 1970 a 1992/1994, a produção dos cinco principais grãos (arroz, feijão, milho, soja e trigo) teve aumento na participação do Centro-Oeste de cerca de 10\% para mais de $20 \%$ do total nacional. A soja, por sua vez, que foi a cultura que apresentou a melhor rentabilidade relativa nesse período, teve uma elevação de sua participação nacional de cerca de 1\% na safra 1968/1970 para cerca de 39\% na safra 1992/1994 (Diniz, 1995), liderado esse crescimento especialmente pelo Estado do Mato Grosso. ${ }^{4}$

Já no período mais recente, nos anos agrícolas 2001/2002, 2002/2003, 2003/ 2004, o crescimento da área plantada no Centro-Oeste foi cerca de $66 \%$, mudando o padrão de crescimento da produção de grãos no País, que, na década de 1990, foi baseado no incremento de produtividade (Brandão, 2005).

Destaque que esse crescimento foi decorrente de uma conjunção favorável de fatores, tanto relacionados ao comportamento dos mercados internacionais das commodities agrícolas, como também espelhando elementos de ordem macroeconômica interna.

Entre 1998 e 2001, a queda persistente dos preços agrícolas, particularmente a da soja, foi compensada pela mudança da política cambial brasileira, com a consequente desvalorização do câmbio em 1999, tendo como efeito apenas estabilizar a queda dos preços domésticos no período (Brandão, 2005).

Assim, a recuperação dos preços internacionais da soja em 2002, tendo a particularidade de durar dois anos consecutivos, na época de plantio, e a queda da safra americana (maior produtor mundial e cuja safra acaba por regular os preços internacionais), entre 2002 e 2003, foram fatores decisivos para estimular o crescimento da área plantada.

A dinâmica do desenvolvimento da soja na região amazônica em anos recentes é fruto do avanço da fronteira agrícola na direção norte a partir do Mato Grosso (Fearnside, 2006) para os Estados fronteiriços, como Pará e Amazonas, mas também outros Estados que apresentavam vantagens comparativas relevantes, como Rondônia, Tocantins, Roraima e Maranhão. A rota de expansão da soja na região sofre influência 
direta do reordenamento territorial do próprio Estado do Mato Grosso, da atuação de grandes grupos econômicos na região, até mesmo com a implantação de plantas esmagadoras de maior escala de produção, e as possibilidades de implantação de projetos de infraestrutura como a Ferronorte (ligando Rondonópolis ao Porto de Santos), o asfaltamento da BR-163 (ligando Cuiabá ao Porto de Santarém) e a construção do Porto Graneleiro de Itacoatiara, para que a produção de soja fosse escoada via BR-164 até Porto Velho e desta a Itacoatiara (Oliveira, 2005; Arima et al., 2005).

Aliada aos fatores acima citados, a expansão da soja na região amazônica foi favorecida por outros elementos que concorrem para a redução de seus custos e o aumento de sua competitividade relativa. O primeiro deles, a topografia da região, já que a mecanização da rodução exige terras planas (Puty et al., 2007), o que torna as terras, como as do Planalto Santareno, por exemplo, bem adaptáveis às necessidades do processo produtivo em larga escala.

Outro fator importante seria o baixo custo de conversão de outros tipos de cultura, como de milho e arroz, e mesmo da própria pecuária, que engendraram um primeiro processo de ocupação do solo na região. Assim, aproveitando-se de terrenos já limpos, ou seja, já desmatados, o custo inicial do investimento se tornou um fator atrativo para a entrada dos sojeiros na região, em grande parte oriundos do Mato Grosso e da região Sul do País. É por isso que alguns autores sustentam que a entrada da soja na região estaria criando um canal de financiamento indireto do desmatamento, a partir da compra de terras já desmatadas, utilizadas em princípio para a extração da madeira e para a pecuária (Puty et al., 2007).

Há de se destacar também um efeito de "demanda derivada" que o crescimento de países como a China e o consequente aumento do consumo per capita de seus residentes por carne, principalmente, suína e de aves, fizeram aumentar a demanda por milho e, particularmente, por soja, como ração animal, gerando uma pressão altista sobre os preços.

Concomitantemente, ocorre a instalação de unidades de beneficiamento e comercialização, multidimensionais de grande penetração no mercado, como a Cargill, a Maggi, a Bunge e a ADM, o que facilitou o crédito e a própria comercialização para os produtores, inclusive os de pequena escala (Diaz apud Arima et al., 2005).

É importante ressaltar que esse é um processo relativamente novo, a partir somente do fim da década de 1990 e que não atinge apenas a Amazônia brasileira (Hecht, 2005). 
O Gráfico 2 ilustra o crescimento da atividade da cultura perene e temporária, separando, entretanto, a produção de grãos - arroz, milho e soja -, no qual se observa, a partir de 2002, um crescimento muito acentuado da área plantada dessas culturas, especialmente da soja.

\section{A causalidade entre fontes principais de desmatamento}

\section{1_Efeito da pecuária}

A direção da causalidade do efeito da pecuária sobre o desmatamento medido pe- lo número de cabeças por município e a densidade dessa na área do município podem ser pensadas de forma bidirecional. De um lado, quanto mais elevado for o tamanho do rebanho bovino em termos da área ocupada do município e quanto maior sua taxa de crescimento, pode-se esperar uma elevação da pressão acerca da conversão da floresta em pasto. Por outro lado, quanto maior a área ocupada com pasto e, portanto, maior o desmatamento já realizado, maior a dinamização dessa atividade, em termos da redução do custo relativo, atraindo novos pecua-

\section{Gráfico 2_ Área plantada de algumas culturas selecionadas nos municípios da Amazônia Legal, no período de 2000 a 2005}

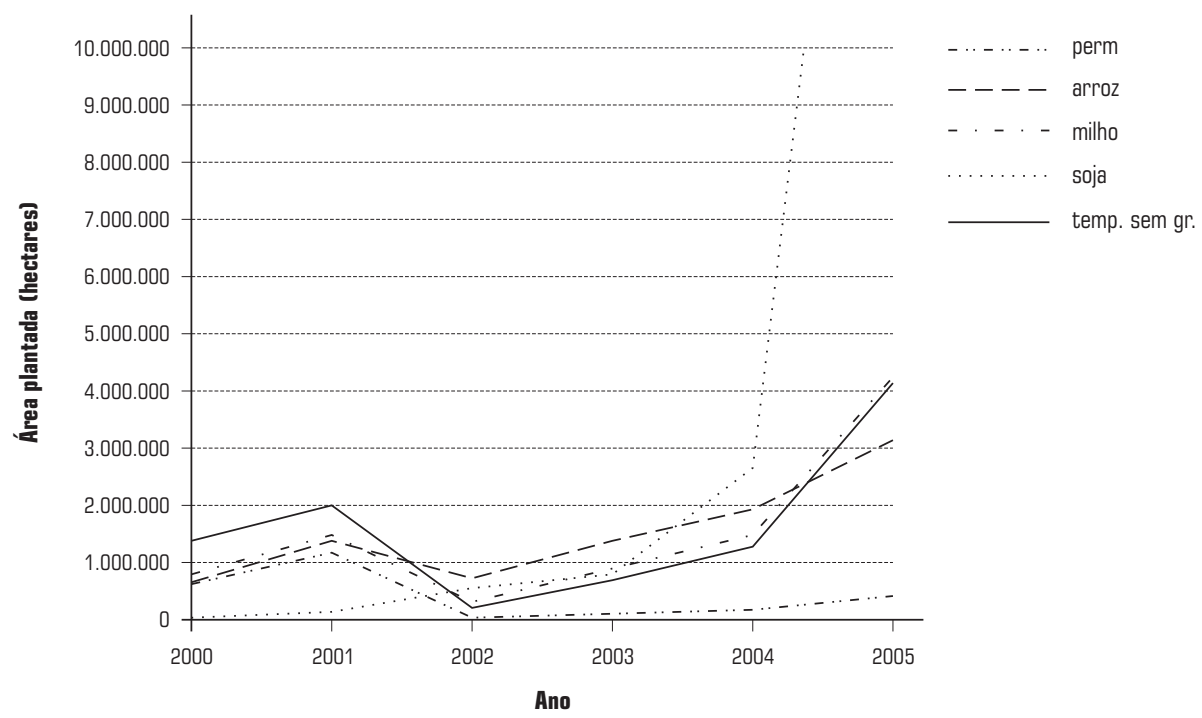


ristas e intensificando essa atividade. Segundo Hecht e Cockburn (1990), a pecuária tornou-se o definitivo uso da terra na Amazônia brasileira, ocupando mais de $85 \%$ da área desmatada, já na década de 1980 .

\section{2_Efeito da agricultura (cultura perene e temporária)}

Tanto a agricultura permanente quanto a temporária reproduzem um efeito bidirecional com o desmatamento. De fato, da mesma forma que ocorre com a pecuária, o desbravamento da fronteira tem efeito redutor de custo, atraindo novos produtores, e mesmo levando a que os antigos tenham acesso a novas áreas antes com floresta primária. Por sua vez, à medida que a atividade cresce, enseja pelos efeitos de escala que novas áreas sejam incorporadas, aumentando a área plantada e a pressão por desmatamento novo. Evidentemente, isso que foi falado acima pode ser pensado em termos da variável área ocupada.

\subsection{Crédito agrícola}

A disponibilidade de crédito é uma variável que também se espera um efeito bidirecional com o desmatamento. De um lado, quanto maior o crédito (esperado) para aplicação em capital fixo e de capital de giro (custeio), maior o incentivo ao investimento "local" e à mobilidade do investimento "externo", isto é, o deslocamento de produtores de outras áreas geográficas do País para realizar empreendimentos na Amazônia Legal, o que induz ao crescimento das atividades devastadoras. De outro, com o crescimento das atividades econômicas em geral (que por suas características cresce desmatando), aumenta a demanda por crédito, o que cria uma força direcional em sentido contrário.

\section{4_PIB "per capita"}

A análise anterior realizada para as atividades econômicas individualmente também reforça que a relação entre PIB per capita e desmatamento deve ser bidirecional. De fato, o crescimento econômico, medido pela evolução do PIB per capita, significa que o conjunto das atividades econômicas do Estado está crescendo, inclusive aquelas que promovem o desmatamento e aumentando mais do que o crescimento populacional. Assim, o ciclo de crescimento no município, com uma disponibilidade maior de renda, cria um efeito indutor a fim de permitir novos investimentos e mesmo atrair investidores de outros lugares, para gozar das externalidades criadas por esses próprios inves- 
$\ldots \ldots \ldots \ldots$ 5 Sabendo-se que parte da mão de obra ocupada na agricultura, especialmente ligada à agricultura familiar, é constituída de menores de 14 anos. tidores, incentivando o desmatamento. Mas, além desse efeito, quando o desmatamento cresce, o avanço de novas áreas pelos produtores antigos e a atração de novos produtores pela queda do custo relativo levam a um efeito posterior de crescimento das atividades devastadoras e, por sua vez, do crescimento econômico como um todo, medido pelo PIB.

\section{5_Educação}

A educação mensurada com base em duas proxies - matrícula de adultos e matrícula para os ensinos fundamental e médio pode ser pensada tendo um efeito bidirecional, no caso da educação de adultos, mas unidirecional, no caso da matrícula de crianças (ensinos fundamental e médio regulares).

No primeiro caso, espera-se a princípio que, quanto maior o contingente de adultos matriculados na escola, menor a disponibilidade de tempo para exercer atividades que promovam o desmatamento, além do que, valendo-se da informação obtida com o aumento da escolaridade, se poderia esperar que o adulto tomasse consciência dos efeitos das atividades degradadoras ao meio ambiente.

Por outro lado, espera-se que exista um efeito do desmatamento sobre a educação, já que, à medida que o desmatamento avança, outras atividades econômicas, como o extrativismo florestal não madeireiro, por exemplo, deixam de ser exploradas, levando os indivíduos a procurarem outras atividades econômicas ou mesmo uma complementação educacional, que os possibilitaria a adquirir trabalho que exige habilidades diferentes daquelas originalmente requeridas.

No segundo caso, quanto maior o número de alunos matriculados nos ensinos médio e fundamental, menor o número de braços disponíveis para, em princípio, exercer atividades devastadoras. ${ }^{5}$

\section{6_Efeito populacional}

O crescimento do contingente populacional certamente é um fator de pressão sobre o meio ambiente, à medida que é um elemento de aumento da intensidade de uso dos recursos naturais. Assim, quanto maior o contingente populacional e quanto maior a densidade demográfica, espera-se maior desmatamento da área do município. Dessa maneira, a priori, também se espera um relacionamento unidirecional entre o efeito populacional e o desmatamento.

\section{Teste de causalidade de Granger}

Nesta seção será descrito o método do teste de causalidade para dados em painel. Segundo Erdil e Yetkiner (2004), a li- 
teratura geralmente não provê métodos muito diversificados para dados em painel em relação ao teste original proposto por Granger (1969). De acordo com esses autores, é possível identificar dois tipos de abordagem. A primeira é proposta por Holtz-Eakin et al. (1985), na qual utilizam um vetor autorregressivo (VAR) para estimar e realizar o teste de causalidade para dados em painel e tratam os coeficientes como variáveis. Esse mesmo procedimento também pode ser visto nos trabalhos de Hsiao (1986 e 1989), Holtz-Eakin et al. (1988), Weinhold (1996 e 1999), Nair-Reichart e Weinhold (2001) e Choe (2003). Já a segunda corrente é liderada por Hurlin e Venet (2001), Hurlin (2004a e 2004b), Hansen e Rand (2004), que também utilizam um vetor autorregressivo (VAR), mas tratam os coeficientes como constantes.

\subsection{Modelo econométrico}

A metodologia aqui descrita será baseada na primeira corrente da literatura descrita acima, mais especificamente em HoltzEakin et al. (1988), uma vez que o painel apresenta uma série temporal relativamente longa, e acredita-se que exista variabilidade dos coeficientes ao longo do período.

Em um contexto usual de séries temporais, a equação de autorregressão bivariada segue a seguinte forma: $y_{t}=\alpha_{0}+\sum_{l=1}^{m} \alpha_{i} y_{t-l}+\sum_{l=1}^{m} \delta_{l} x_{t-l}+u_{t}$

onde os $\alpha^{\prime} s$ e os $\delta$ 's são coeficientes da projeção linear de $y_{t}$ na constante e nos valores de $y_{t}$ e $x_{t}$, e o tamanho do lag, $m$, é suficientemente grande para garantir que $u_{t}$ seja um ruído branco. Não necessariamente os tamanhos dos lags de $y_{t} \mathrm{e}$ $x_{t}$ serão iguais, entretanto, assume-se que sejam.

Como em geral dados em painel têm grande número de unidades cross-sectional, onde cada unidade possui poucas observações temporais, então, para estimar a equação (1), é preciso impor restrições que garantam a mesma estrutura para cada uma dessas unidades. Um caminho seria relaxar a restrição de pooling em favor de um efeito individual que transcende na prática para um intercepto individual específico. Mudanças no intercepto de um vetor autorregressivo estacionário correspondem às mudanças nas médias das variáveis, assim permitindo efeitos individuais e consequentemente heterogeneidade individual no nível das variáveis de $x$ e $y$. Um segundo caminho seria acomodar a heterogeneidade individual, permitindo a variância da inovação na equação (1) variar com a unidade cross-sectional. $\mathrm{Mu}$ dança na variância da inovação de um vetor autorregressivo corresponde à mudança na variância das variáveis, possibilitando, desta 
forma, heterocedasticidade cross-sectional na variância da inovação e, por sua vez, permitindo heterogeneidade individual na variabilidade de $x$ e $y$. Portanto, assume-se tanto efeito individual quanto heterocedasticidade nas unidades cross-sectional.

É provável que o nível e a variabilidade das variáveis sejam importantes fontes de heterogeneidade individual, mas também se poderia admitir heterogeneidade individual no padrão da correlação das séries de tempo de $x$ e $y$. Entretanto, permitir uma heterogeneidade semelhante é complicado, uma vez que as variáveis do lado direito da equação (1) são variáveis endógenas defasadas. Desta forma, segundo Pakes e Griliches (1984), fica difícil interpretar os $\alpha^{\prime} s$ e os $\delta^{\prime} s$ como médias dos parâmetros que variam aleatoriamente entre os indivíduos das unidades cross-sectional, ainda que essa interpretação seja possível quando essas variáveis são exógenas.

Por outro lado, pooling de unidades cross-sectional possui certas vantagens. Primeiro, a suposição de estacionaridade pode ser relaxada. A presença de um grande número de unidades cross-sectional torna possível permitir que os coeficientes defasados variem no tempo. Segundo, a teoria da distribuição assintótica para um grande número de unidades cross-sectional não requer que o vetor autorregressivo satisfaça a condição usual que exclui a raiz explosiva do processo.
Dessa maneira, pode-se derivar um modelo que relaxe as suposições acima. Assuma que existam $N$ unidades no cross-section e $T$ períodos de tempo, com $i$ indexando as unidades do cross-section, e $t$, os períodos. Assim, o modelo que permite efeitos individuais e não estacionaridade entre os períodos de tempo é dado da seguinte forma:

$$
\begin{aligned}
y_{i t}= & \alpha_{0 t}+\sum_{l=1}^{m} \alpha_{l t} y_{i t-l}+ \\
& +\sum_{l=1}^{m} \delta_{l t} x_{i t-l}+\psi_{t} f_{i}+u_{i t}
\end{aligned}
$$

$\operatorname{com}(i=1, \ldots ., N ; t=1, \ldots, T)$, onde $f_{i}$ é um efeito individual não observado e $\alpha_{0 t}, \alpha_{1 t}, \ldots, \alpha_{m t} ; \delta_{1}, \ldots, \delta_{m t} ; \psi_{t}$ são coeficientes de projeção linear de $y_{i t}$ na constante, valores passados de $y_{i t}$ e $x_{i t}$, e no efeito no individual $f_{i}$.

A especificação da equação (2) como uma projeção implica que o termo do erro $u_{i t}$ satisfaz a condição de ortogonalidade.

$$
\begin{aligned}
E\left[y_{i s} u_{i t}\right] & =E\left[x_{i s} u_{i t}\right]= \\
& =E\left[f_{i} u_{i t}\right]=0,(s<t)
\end{aligned}
$$

Essa condição de ortogonalidade pressupõe que as variáveis defasadas de $x \mathrm{e}$ $y$ são instrumentos qualificados para a equação (2).

Em um painel estático, o procedimento usual para remoção do efeito indivi- 
dual é o uso do estimador conhecido como within estimator, no qual todas as variáveis são transformadas, subtraindo-se seus valores de suas médias temporais (para cada unidade transversal). No entanto, em um contexto dinâmico, graças à presença de variáveis endógenas defasadas, tal procedimento gera estimadores inconsistentes (Nickell, 1981).

Como alternativa, Holtz-Eakin et al. (1988) sugerem diferenciar a equação (2) para retirar $f_{i}$ e então - para evitar a correlação entre a primeira defasagem da variável dependente e o erro - empregar um estimador de variáveis instrumentais. Vale salientar que essa transformação só será possível se as variáveis forem estacionárias. Assim, a equação (2) diferenciada é escrita na forma:

$$
\begin{aligned}
y_{i t}-y_{i t-1} & =\alpha_{t}+\sum_{l=1}^{m} \alpha_{l}\left(y_{i t-l}-y_{i t-l-1}\right)+ \\
& +\sum_{l=1}^{m} \delta_{l}\left(x_{i t-l}-x_{i t-l-1}\right)+v_{i t}
\end{aligned}
$$

Onde existem somente $2 m+1$ variáveis do lado direito, o que implica que só existiram instrumentos suficientes para identificar os parâmetros se $t \geq m+2$. No caso estacionário, será possível obter as estimativas das variáveis defasadas quando $T \geq m+2$.

\section{2_ Estimação do modelo}

A inferência em equações de regressão dinâmica é tipicamente baseada em grandes amostras assintóticas, isto é, para $T \rightarrow+\infty$ onde $T$ indica o número de períodos de tempo das variáveis envolvidas na amostra. Em econometria, o modelo de relacionamento dinâmico usualmente requer a inclusão de defasagens na variável dependente. Uma observação importante que se faz a esse tipo de modelo é que, quando o número de período temporal é relativamente pequeno, a aproximação padrão assintótica é pobre (Nankervis e Savin, 1987). Em geral, apesar de serem consistentes e assintoticamente eficientes, os estimadores são seriamente viesados em pequenas amostras.

No caso do modelo de painel dinâmico, a aproximação assintótica pode ser para $T \rightarrow+\infty$ ou $N \rightarrow+\infty$ para ou ambos, onde $N$ indica o número de unidades observadas em cada cross-section para a amostra longitudinal. Na prática, $T$ é geralmente muito pequeno, e $N$ é razoavelmente grande. A eficiência de vários tipos de estimador em modelos de componente de erro dinâmico e modelos de efeito fixo dinâmico tem sido o tema central de vários estudos teóricos e estudos de Monte Carlo, como, por exemplo, Balestra e Nervole 
(1966), Nervole (1971), Maddala (1971) e Arellano e Bond (1991). A ideia é encontrar o viés para pequenas amostras aplicando técnicas econométricas em um contexto de regressão multivariado dinâmico; ver, por exemplo, Kiviet e Phillips (1993 e 1994).

A especificação econométrica do modelo aqui utilizado é baseada na suposição de que o quadro corrente que caracteriza a variável dependente tende a se perpetuar e/ou influenciar o desempenho dos principais determinantes dessa variável no futuro. Para levar em consideração esse comportamento dinâmico, essa relação é investigada por meio de um modelo de regressão para dados em painel dinâmico definido da seguinte forma:

$$
\begin{aligned}
y_{i t}= & \alpha_{0 t}+\sum_{l=1}^{m} \alpha_{l t} y_{i t-l}+ \\
& +\sum_{l=1}^{m} \delta_{l t} x_{i t-l}+\eta_{i}+\varepsilon_{i t}
\end{aligned}
$$

onde $\eta$ representa os efeitos fixos não observáveis dos indivíduos, e $\varepsilon_{i t}$ são os distúrbios aleatórios. Em todas as variáveis do modelo (5), o subscrito $i$ representa a unidade cross-section, e $t$, o período de tempo.

O modelo acima assume, segundo Ahn e Schmidt (1995), algumas hipóteses, tais como: $E\left[\eta_{i}\right]=E\left[\varepsilon_{i t}\right]=E\left[\eta_{i} \varepsilon_{i t}\right]=0$, $E\left[\varepsilon_{i t} \varepsilon i s\right]=0$ para $i=1,2, \ldots, \mathrm{N}$ e qualquer $t \neq s$, bem como uma hipótese rela- tiva às condições iniciais $E\left[y_{i 1} \varepsilon_{i t}\right]=0 \mathrm{pa}$ ra $i=1,2, \ldots, N$ e $t=1,2, \ldots, T$.

As técnicas de estimação tradicionais são inapropriadas no caso da equação (5) em razão de alguns problemas econométricos. Um exemplo seria a presença dos efeitos não observáveis dos indivíduos, $\eta_{i}$, juntamente com a variável dependente defasada, $y_{i t-l}$, no lado direito da equação. Nesse caso, omitir os efeitos fixos individuais no modelo dinâmico em painel torna os estimadores de mínimos quadrados ordinários (MQO) enviesados e inconsistentes. Para corrigir esses problemas, Arellano e Bond (1991) propõem um estimador do método dos momentos generalizado-diferenciado (MMG-diferenciado). Tal método consiste na eliminação dos efeitos fixos através da primeira diferença da equação (5),

$\Delta y_{i t}=\sum_{l=1}^{m} \alpha_{l} \Delta y_{i t-l}+\sum_{l=1}^{m} \delta_{l} \Delta x_{i t-l}+\Delta \varepsilon_{i t}$

onde para uma variável $z_{\text {it }}$ qualquer, $\Delta z_{i t}=z_{i t}-z_{i t-1}$.

Observe que, pela construção da equação (6), $\Delta y_{i t-l}$ e $\Delta \varepsilon_{i t}$ são correlacionados e, portanto, estimadores de MQO para seus coeficientes serão enviesados e inconsistentes. Nesse caso, é necessário empregar variáveis instrumentais para $\Delta y_{i t-l}$. O conjunto de hipóteses adotadas na equação (5) implica que as condições de momentos 
$E\left[\Delta y_{i t-l} \Delta \varepsilon_{i t}\right]=0$, para $t=3,4, \ldots ., T \mathrm{e}$ $l \geq 2$, são válidas. Baseados nesses momentos, Arellano e Bond (1991) sugerem empregar $\Delta y_{i t-l}$, para $t=3,4, \ldots ., T$ e $l \geq 2$, como instrumentos para a equação (6). Por sua vez, esse estimador também permitiria utilizar como instrumentos a primeira diferença dos regressores estritamente exógenos.

Arellano e Bond (1991) derivaram duas versões para os estimadores de GMM. $\mathrm{Na}$ primeira, conhecida como estimador one-step, supõe-se que os termos de erro são independentes e homocedásticos nas unidades de cross-section e, ao longo do tempo, ao passo que, na segunda, chamada de two-step, os resíduos gerados na primeira etapa são empregados para obter uma estimativa consistente da matriz de variânciacovariância, permitindo relaxar as hipóteses de independência e consistência. Assintoticamente, os dois estimadores são equivalentes, porém o two-step não necessita conhecer a priori a distribuição dos componentes $\eta_{i}$ e $\varepsilon_{i t}$. Todavia, tem sido observado em diversos estudos que essa versão do estimador de GMM os desvios padrões tendem a ser viesados para baixo em pequenas amostras, recomendando nesse caso o uso da versão one-step.

Por fim, é recomendada a realização de um teste de especificação do modelo e, por sua vez, a consistência do estimador
GMM, bem como testar a existência de correlação serial, em que os referidos autores propõem um teste direto nos resíduos da especificação em primeira-diferença que também pode ser útil para verificar a consistência do estimador de GMM. ${ }^{6}$

Então, seguindo Holtz-Eakin et al. (1988), a existência de causalidade no sentido de Granger é verificada através do teste de restrições de Wald, aplicado aos parâmetros estimados pelo método GMM descrito anteriormente. Partindo-se da equação (6), estimam-se os seguintes modelos:

$$
\begin{aligned}
\Delta y_{i t}= & \sum_{l=1}^{m} \alpha_{1 l} \Delta y_{i t-l}+ \\
& +\sum_{l=1}^{m} \delta_{1 l} \Delta x_{i t-l}+\Delta \varepsilon_{i t} \\
\Delta x_{i t}= & \sum_{l=1}^{m} \delta_{2 l} \Delta x_{i t-l}+ \\
& +\sum_{l=1}^{m} \alpha_{2 l} \Delta y_{i t-l}+\Delta \mu_{i t}
\end{aligned}
$$

Dessa forma, haverá causalidade de Granger unidirecional de $x$ para $y$ se nem todos os $\delta_{1 l}{ }^{\prime} s$ forem iguais a zero em (7), mas todos os $\alpha_{2 l}{ }^{\prime} s$ forem iguais a zero em (8). De forma oposta, haverá causalidade no sentido de Granger unidirecional de $y$ para $x$ se todos os $\delta_{1 /}$ 's forem iguais a zero em (7), porém nem todos os $\alpha_{2 l}{ }^{\prime} s$ forem iguais a zero em (8). Pode haver causa- $\cdots \cdots \cdots$

6 A ausência de correlacão serial está associada à falha em rejeitar a hipótese nula de autocorrelação de segunda ordem, sugerindo nesse caso que o estimador de GMM é consistente (Arellano e Bond, 1991). 
lidade de Granger bidirecional entre $x$ e $y$ se nem todos $\delta_{1 l}{ }^{\prime} s$ e $\alpha_{2 l}{ }^{\prime} s$ forem iguais a zero. Por fim, podem ocorrer situações em que não há causalidade de Granger entre $x$ e $y$, para isso basta que os $\delta_{1 l}^{\prime} s$ e todos os $\alpha_{2 l}$ 's sejam iguais a zero.

\section{5_Descrição das variáveis e dados utilizados}

Entre a metade da década de 1990 e 2006, o número de municípios criados não foi grande, tal que a comparação espacial em nível municipal nesse período não causa problemas significativos. Ademais, por deficiência nos dados, como omissão de variáveis, alguns municípios criados no período foram omitidos na amostra.

Assim, os dados utilizados para o modelo compreenderam o período de 1997 a 2006, e algumas séries tiveram dados interpolados para alguns anos. Neste caso, dois procedimentos foram utilizados: o cálculo da variável a partir da média (móvel), com base nos dados observados (existentes), ou o cálculo da variável a partir de sua taxa de crescimento. Ao final, foram retirados aqueles municípios cujo comportamento estimado descrevia um possível "outlier".

Assim, o modelo foi estimado com 445 municípios dos Estados integrantes da Amazônia Legal: Rondônia, Amazonas,
Acre, Amapá, Roraima, Pará, Maranhão, Mato Grosso e Tocantins.

A escolha das variáveis explicativas ficou refém da disponibilidade dos dados para o período, pelo menos para os anos de 1997 e 2006. Todavia, foram considerados como os grandes vetores do desmatamento dois grandes grupos: o primeiro caracterizando a ocupação do solo - mais especificamente variáveis que evidenciam o setor agropecuário - uma vez que, como apontado pela literatura, outros fatores como infraestrutura, por exemplo, são facilitadores que aumentam a intensidade dos fatores causais primários, no caso: pecuária, cultura permanente e cultura temporária. Já o segundo grupo de variáveis representa as características socioeconômicas dos municípios.

Ademais, foram utilizadas as seguintes variáveis que tiveram como principais fontes o IPEA/Instituto de Pesquisa Econômica Aplicada (http://www.ipea.gov.br), o IBGE/Instituto Brasileiro de Geografia e Estatística (http://www.ibge.gov.br) e o INEP/Instituto Nacional de Estudos e Pesquisas Educacionais (http://www.inep.gov. br), com base na literatura pertinente:

a. Desmatamento $=$ Total de hectares desmatado por município $i$;

b. Grupo de variáveis do setor agropecuário: 
i. Rebanho bovino $=$ Total do rebanho bovino do município $i$;

ii. Densidade bovina $=$ Total do rebanho do município $i$ dividido pelo total da área ocupada do município $i$ em hectare;

iii. Culturas permanentes $=$ Somatório do total da utilização das terras em lavouras permanentes em hectare do município $i$;

iv. Cultura temporária = Somatório do total da utilização das terras em lavouras temporárias em hectare do município $i$;

v. Área ocupada $=$ Total $\mathrm{da}$ área ocupada do município $i$ com a agropecuária.

c. Grupo de variáveis socioeconômicas:

i. PIB per capita $=$ Produto Interno Bruto (PIB) do município $i$ dividido pela população total do município $i$. Reais de 2.000 deflacionados pelo deflator implícito do PIB nacional;

ii. Educação de adultos = Número de adultos matriculados nos ensinos fundamental e médio no município $i$, segundo a classificação usualmente adotada pelo INEP; iii. Matrícula $=$ Número de alunos matriculados no ensino fundamental regular no município $i$, segundo a classificação usualmente adotada pelo INEP;

iv. Crédito agrícola $=$ Total de crédito agrícola contratado no município $i$;

v. População = População total residente no município $i$;

vi. Densidade demográfica $=$ População total residente no município $i$ dividido pela área total do município $i$ em $\mathrm{km}^{2}$.

\section{Resultados empíricos}

\subsection{Teste de raiz unitária para dados em painel}

Para evitar o problema de regressão espúria na estimação dos modelos em painel, faz-se necessária a ausência de processo de raiz unitária em cada variável, isto é, que as variáveis sejam estacionárias. Diversos são os testes de raiz unitária para dados em painéis. Tais testes podem ser classificados em dois grupos. O primeiro grupo incorpora aqueles testes que assumem a existência de um processo de raiz unitária comum, tal que os parâme- 
tros para persistência são idênticos entre os cross-sections. Integram esse grupo os testes propostos por Levin, Lin e Chu (2002) e o de Breitung (2000) e podem ser considerados como um teste de Dickey-Fuller Aumentado (ADF) com dados agrupados. A hipótese nula é a de que existe um processo de raiz unitária comum entre os cross-sections do painel, contra a hipótese alternativa de que todos os cross-sections são estacionários.

Como descrito na seção anterior, é preciso que as variáveis do painel sejam estacionárias para que se possa trabalhar com as variáveis em primeira diferença e com isso eliminar os efeitos individuais presentes.

Diversos são os testes que exploram a conformação de painéis para o teste de integração de variáveis macroeconômicas. Os testes que são encontrados podem ser classificados em dois grupos. O primeiro grupo incorpora aqueles testes que assumem a existência de um processo de raiz unitária comum, tal que os parâmetros para persistência para cada unidade (ou grupo) possuem a mesma estrutura autorregressiva (AR (1)), além de permitir a existência do efeito individual. Integram esse grupo os testes propostos por Levin, Lin e Chu (2002) e o de Breitung (2000) e podem ser considerados como um teste de DickeyFuller Aumentado (ADF) com dados agru- pados. A hipótese nula é a de que cada série do painel seja integrada de ordem um, contra a hipótese em que todas as séries sejam estacionárias.

O outro grupo incorpora os testes que permitem a existência de um processo individual de raiz unitária de forma que os parâmetros de persistência podem variar livremente para cada unidade (grupo). Por isso, os testes são construídos com base nas estatísticas individuais. Por exemplo, a estatística de teste proposta por Im, Pesaran e Shin (1997 e 2003) é o resultado de uma média das t-estatísticas de DickeyFuller sobre cada unidade do painel. A hipótese nula assume que todos os cross-sections são não estacionários, enquanto, na hipótese alternativa, pelo menos um cross-section é estacionário. $\mathrm{O}$ teste adquire a estrutura do $\mathrm{ADF}$ ao permitir que as defasagens para a variável dependente possam ser inseridas, o que possibilita a autocorrelação do erro para cada série.

Foram utilizados, no presente trabalho, os testes propostos por Levin, Lin e Chu (2002), (LLC), e o teste de Im, Pesaran e Shin (2003), (IPS). Os testes foram realizados para as séries em nível, utilizando-se o critério de seleção para o número de defasagens de Hannan-Quinn. A Tabela 1 apresenta os resultados. 
Tabela 1_ Testes de raiz unitária em painel

(probabilidade)

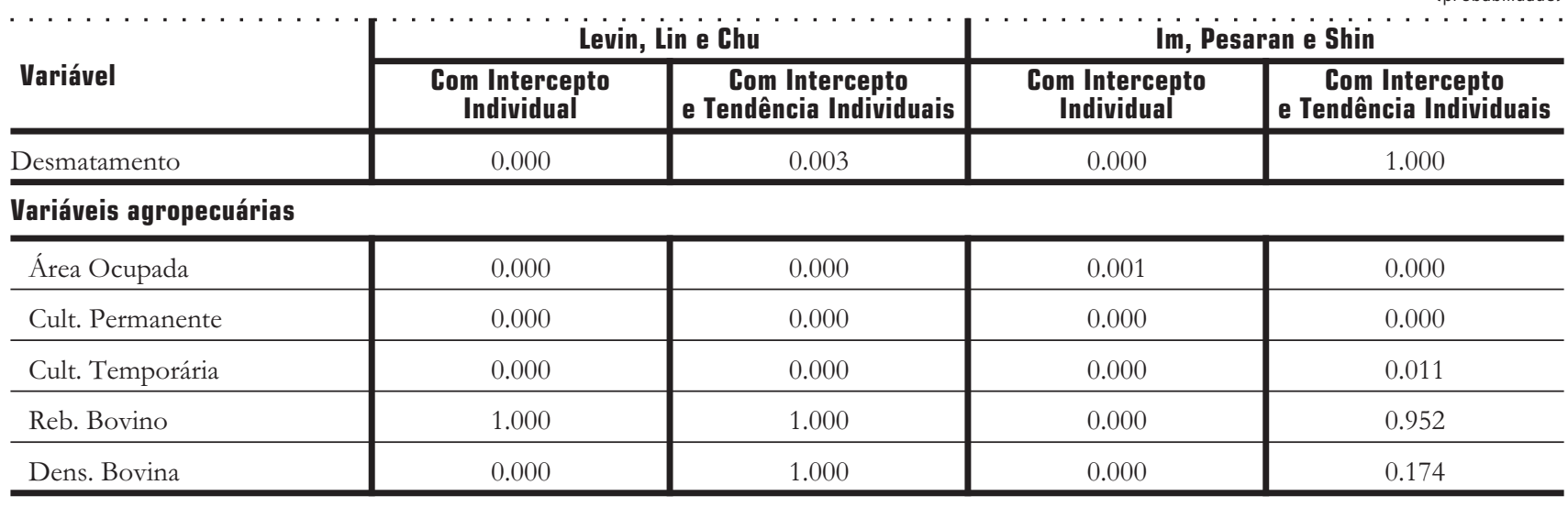

Variáveis socioeconômicas

\begin{tabular}{|c|c|c|c|c|}
\hline Educ. Adulto & 0.000 & 0.000 & 1.000 & 0.275 \\
\hline Crédito Agrícola & 0.000 & 0.000 & 0.000 & 0.000 \\
\hline Matrícula & 0.000 & 0.000 & 1.000 & 0.002 \\
\hline PIB per capita & 0.000 & 0.000 & 0.000 & 0.000 \\
\hline População & 0.000 & 0.000 & 1.000 & 1.000 \\
\hline Dens. Demográfica & 0.000 & 0.000 & 1.000 & 1.000 \\
\hline
\end{tabular}

Fonte: Elaboração dos autores.

Notas: As defasagens para os testes foram determinadas pelo critério de Hannan-Quinn.

As probabilidades para os testes assumem normalidade assintótica.

Teste Levin, Lin e Chu - Hipótese nula: raiz unitária (assume processo de raiz unitária comum).

Teste Im, Pesaran e Shin - Hipótese nula: raiz unitária (assume processo de raiz unitária individual).

Como pode ser observado, todas as variáveis consideradas são estacionárias em pelo menos um dos testes em um nível de $5 \%$ de significância. A variável Desmatamento é estacionária em ambos os testes, com exceção do teste de Im, Pesaran e
Shin, quando se considera o intercepto e a tendência individual; Rebanho Bovino é estacionária, considerando o teste de Im, Pesaran e Shin e apenas o intercepto individual; Educação de Adultos é estacionária apenas no teste de Levin, Lin e Chu, consi- 
derando tanto o intercepto individual quanto o intercepto mais tendência individual; Matrícula é estacionária em ambos os testes, com exceção do teste de Im, Pesaran and Shin, quando se considera apenas o intercepto individual; já as variáveis Área Ocupada, Cultura Permanente, Cultura Temporária, Crédito Agrícola e PIB per capita são estacionárias em ambos os testes e considerando tanto o intercepto individual quanto o intercepto e a tendência individual.

\section{2_ Teste de causalidade de Granger}

Os resultados para o teste de causalidade de Granger para relação entre desmatamento e as variáveis explicativas podem ser observados na Tabela 2. Essa traz as descrições das variáveis, o número de defasagens utilizadas, a estatística de Wald, bem como o p-valor para cada uma delas e as respectivas hipóteses nulas. Foi considerado o nível de significância de 5\% e também duas ou três defasagens.

Pode-se observar uma causalidade de Granger bidirecional entre desmatamento e todas as variáveis agropecuárias - Área Ocupada, Culturas Permanentes, Culturas Temporárias, Rebanho Bovino e Densidade Bovina. Os resultados foram, de certa forma, esperados, uma vez que, na medida que cresce o tamanho da área desmatada, aumenta a pressão sobre as variáveis em questão e vice-versa, como descrito na seção inicial.

Observa-se também, com relação ao grupo de variáveis socioeconômicas, que existe uma causalidade bidirecional com as variáveis Crédito Agrícola, Educação de Adultos e Densidade Demográfica. Resultados também esperados, uma vez que existe endogeneidade entre essas variáveis e o processo de desmatamento.

Os resultados também mostraram uma relação unidirecional no sentido do desmatamento para Matrícula. Esse resultado pode ser em decorrência do processo de exaustão dos recursos naturais, bem como da baixa remuneração da atividade extrativista, que leva as famílias a procurar qualificar-se na busca de melhores condições de vida.

Por fim, com relação às variáveis PIB per capita e População, o efeito da causalidade foi unidirecional no sentido dessas para o desmatamento. Esse resultado era esperado já que, à medida que se aumenta o grau de atividade econômica, bem como o contingente populacional do município, se esperava que se intensificasse o processo de desmatamento, visto que essas atividades estão, em sua maioria, ligadas a atividades extrativistas. 
Tabela 2_ Teste de causalidade de Granger em painel entre desmatamento e as variáveis agropecuárias e as socioeconômicas $\left.\begin{array}{l}\text { Variável Explicativa } \\ \begin{array}{c}\text { Defasagem } \\ \text { Explicativa no sentido de Granger }\end{array}\end{array}\right] \begin{gathered}\text { Ho Des: Variável Explicativa não causa } \\ \text { Desmatamento no sentido de Granger }\end{gathered}$

\section{Variáveis agropecuárias}

\begin{tabular}{l|c|c|c|c|c}
\hline Área Ocupada & 3 & 15.23028 & 0.0000 & 12.36575 & 0.0000 \\
\hline Cult. Permanente & 3 & 16.32561 & 0.0000 & 6.215846 & 0.0003 \\
\hline Cult. Temporária & 3 & 9.865774 & 0.0000 & 20.54645 & 0.0000 \\
\hline Rebanho Bovino & 3 & 12.58753 & 0.0000 & 36.52262 & 0.0000 \\
\hline Densidade Bovina & 2 & 56.36550 & 0.0000 & 40.02216 & 0.0000 \\
\hline
\end{tabular}

\section{Variáveis socioeconômicas}

\begin{tabular}{|c|c|c|c|c|c|}
\hline Credito Agrícola & 3 & 28.61936 & 0.0000 & 13.18505 & 0.0000 \\
\hline Educação Adulto & 2 & 25.13541 & 0.0000 & 14.99244 & 0.0000 \\
\hline Matrícula & 3 & 12.80666 & 0.0000 & 1.096093 & 0.3495 \\
\hline PIB per capita & 3 & 1.973909 & 0.1158 & 11.88900 & 0.0000 \\
\hline População & 3 & 0.119835 & 0.9485 & 1478.605 & 0.0000 \\
\hline
\end{tabular}

Fonte: Elaboração dos autores.

Obs.: O número de defasagem foi estabelecido de acordo com a maioria dos resultados fornecidos pelos critérios de escolha Akaike, Schwarz, Hannan-Quinn, FPE (Forecast Prediction Error) e pelo teste likelihood ratio (LR) em um máximo de até três defasagens.

\section{7_Considerações finais}

O trabalho teve como objetivo testar a relação causal entre Desmatamento e dois conjuntos de variáveis: um grupo de cinco variáveis agropecuárias (Área Ocupada, Culturas Permanente e Temporária, Rebanho Bovino e Densidade Bovina), representando as variáveis ligadas ao uso do solo e um grupo de seis variáveis representando o lado socioeconômico da região da Amazônia Legal, em nível de município, no período de 1997 a 2006.
Os resultados empíricos para o grupo de variáveis agropecuárias mostraram que existe causalidade bidirecional entre o desmatamento e todas as cinco variáveis de referência desse grupo. Esses resultados, de certa forma, são coerentes com a literatura especializada no tema, uma vez que essa enfatiza que a intensidade do desmatamento na região tem forte correlação com a intensidade do uso do solo (Nepstad et al., 2001; Mertens et al., 2002; Kaimowitz et al., 2004; Alencar et al., 2004). 
Quanto ao grupo de variáveis socioeconômicos, pode-se observar que, nas variáveis de educação, ocorreu uma causalidade unidirecional do Desmatamento para a variável Matrícula, que corresponde à matrícula no ensino fundamental regular, bem como uma causalidade bidirecional entre o Desmatamento e a Educação de Adultos. Esse resultado está diretamente ligado à dinâmica de ocupação das áreas desmatadas, visto que essas atraem famílias com baixo nível de escolaridade e com um número considerável de crianças com idade escolar, o que pressiona a demanda por esses serviços.

Quanto às variáveis populacionais, os resultados mostraram uma causalidade unidirecional do Total da População para o Desmatamento, bem como uma bicausalidade entre a Densidade Populacional e o Desmatamento. Já a variável PIB per capita apresentou uma causalidade unidirecional dela para o Desmatamento, e a variável Crédito Agrícola apresentou uma bicausalidade. Estes últimos resultados estão diretamente ligados à intensidade de atividade econômica dos municípios, como também estão interligados entre si, o que corrobora a ideia de que, à medida que a atividade econômica do município cresce, se intensificam os atrativos populacionais, bem como a pressão sobre os recursos naturais. 


\section{Referências bibliográficas}

AHN, S. C.; SCHMIDT, P. Efficient estimation of models for dynamics panel data. 1995. Mímeo.

ALENCAR, A.; NEPSTAD, D.; MCGRATH, D.; MOUTINHO, P.; PACHECO, P; DEL CARMAN, M.; DIAZ V.; SOARES FILHO, B. S.

Desmatamento na Amazônia: indo além da "emergência crônica". Belém-Pa: IPAM, 2004.

ANDERSEN, Lykke E. Cost-Benefit analysis of deforestation in the Brazilian Amazon. IPEA: Rio de Janeiro, 1997.

ANDERSEN, Lykke E. et. al. The dynamics of deforestation and economic growth in the Brasilian Amazon. Cambridge, UK: Cambridge University Press, 2002.

ANGELSEN, A.; KAIMOWITZ, D. Rething the causes of deforestation: lessons from economic models. The World Research Observer, v. 14, n. 1, p. 73-98, Feb. 1999.

ANDERSON, A. B. (Ed.). Alternatives to deforestation: steps towards sustainable utilization of Amazon forest. New York: Columbia University Press, 1990.
ARELLANO, Manuel; BOND, Stephen. Some tests of specification for panel data: Monte Carlo evidence and an application to employment equations. The Review of Economic Studies, v. 58, n. 2, p. 277-297, Apr. 1991.

ARIMA, E.; BARRETO, P.; BRITO, M. Pecuária na Amazônia: tendências e implicações para a conservação ambiental. Belém-PA: Instituto do Homem e Meio Ambiente da Amazônia, 2005.

BALESTRA, P.; M. NERVOLE. Pooling cross-section and time series data in the estimation of a dynamic model: the demand for natural gas.

Econometrica, v. 34, p. 585-612, 1966.

BECKER, Bertha K. Amazônia. São Paulo: Ática, 1990. (Série Princípios).

BECKER, Bertha K. Amazônia: geopolítica na virada do III milênio. Rio de Janeiro: Garamond, 2006.
BRANDÃO, A. S. P.; REZENDE, G. C.; MARQUES, R. W. C. Crescimento agrícola no período 1999-2004, explosão da área plantada com soja e meio ambiente no Brasil. Rio de Janeiro: IPEA, 2005. (Texto para discussão, 1062).

BREITUNG, J. The local power of some unit root tests for panel data. In: BALTAGI, B. (Ed.).

Nonstationary Panels, Panel

Cointegration, and Dynamic Panels. Advances in Econometrics. JAI: Amsterdam, 2000. v. 15, p. 161-178.

BUCHINSKY, M. Recent advances in quantile regression models - a pratical guideline for empirical research. Journal of

Human Resources, v. 33, p. 88-126, 1998.

CAVENDISH, William. Empirical regularities in poverty-environment relationship of African Rural Households. WPS 99-21, Sept. 1999.

CEPAL. Análise Ambiental e de Sustentabilidade do Estado do Amazonas. Santiago, jun. 2007. 202p. (Publicações das Nações Unidas).
CHOE, J. I. Do foreign direct investment and gross domestic investment promote economic growth? Review of Development Economics, v. 7, p. 44-57, 2003.

CHOMITZ, Kenneth (Org.). At Loggerheads? Agricultural expansion, poverty reduction, and environment in the tropical forests. World Bank Policy Research Report, 2007.

DINIZ, Clélio Campolina. A dinâmica regional recente da economia brasileira e suas perspectivas. Rio de Janeiro: IPEA, 1995. (Texto para discussão, 375).

DINIZ, Marcelo B.; SANTOS, Ricardo B. N.; DINIZ, Márcia J. T.; PUTY, Cláudio, C. B.; RIVERO, Sérgio L. de M. A Amazônia (Legal) brasileira: evidências de uma condição de armadilha da pobreza? In: Encontro Nacional de Economia, 35., 2007, Recife. Anais... Recife-PE: ANPEC, 2007.

DURLAUF, S. N.; JOHNSON, P. Multiple regimes and cross-country growth behaviour. Journal of Applied Econometrics, v. 10, n. 4, p. 365-384, 1995. 
DURLAUF, S. N.,

KOURTELLOS, A.; MINKIN,

A. The local solow growth model.

European Economic Review, v. 45, n. 4-6, p. 928-940, 2001.

ERDIL, Earkan; YETKINER, I.

Hakan. A panel data approach

for income-bealth causality.

Hamburg University, 2004.

(FNU - 47).

FEARNSIDE, Phillipe. Efeitos

de uso de terra e manejo florestal no ciclo de carbono na Amazônia brasileira. In: FLEISCHRESSER,

V. (ed.) Causas e dinâmica do desmatamento na Amazônia.

Brasília, DF, Brasil: Ministério do Meio Ambiente, 2001.

p. 173-196.

\section{FEARNSIDE, Philip. M.}

Desmatamento na Amazônia: dinâmica, impactos e controle.

Manaus, Acta Amazônia, v. 36, n. 3, 2006

\section{FEARNSIDE, Philip. M.}

Amazon Forest maintenance as a source of environmental services. Annals of the Brazilian Academy of Sciences, v. 80, n. 1 , p. 101-114, 2007.

FERREIRA, L. V.; VENTICINQUE, E.;

ALMEIDA, S. O desmatamento na Amazônia e a importância das áreas protegidas. Estudos

Avançados, v. 19, n. 53, p.157-166, 2005.
GARCIA, Ricardo Alexandrino; SOARES-FILHO, Britaldo Silveira; MORO, Sueli. Modelagem espacial do desmatamento amazônico. In: Encontro da Associação de Estudos Populacionais, 15., 2006, Caxambú. Anais... Campinas : ABEP, 2006. p. 1-19.

GEIST, Helmut J.; LAMBIN, Eric F. What drives tropical deforestation? Land-Use and Land-Cover Change (LUCC); International Human Dimensions Programme on Global Environmental Change (IHDP); International Geosphere-Biosphere Programme (IGBP), LUCC Report Series n. 4. Louvain-la-Neuve, 2001.

\section{GRANGER, C. W. J.}

Investigating causal relations by econometric models and cross-spectral methods. Econometrica, v. 37 , p. 424-438, 1969.

GUILHOTO, J. J. M. et al. PIB da agricultura familiar: Brasil-Estados. Brasília: MDA, 2007. (NEAD Estudos, 19).

HANSEN, B. E. Sample splitting and threshold estimation.

Econometrica, v. 68, n. 3, p. 575-603, 2000.

HANSEN, H.; RAND. On the causal links between FDI and growth in developing countries. Development Economics Research Group (DERG), Institute of Economics, University of Copenhagen, 2004. Miméo.
HAYASHI, Fumio. Econometrics. Princeton New Jersey, USA: Princeton University Press, 2000.

HECHT, S. Soybean production, development and conservation on an Amazon Frontier. Development and Change, v. 36, n. 2, 2005. p. $375-404$.

HECHT, S; COCKBURN A. The fate of the forest. Developers, destroyers and defenders of the Amazon. Harper Collins, 1990. $357 \mathrm{p}$.

HECHT, S.; NORGAARD, R. B.; POSIO, G. The economics of cattle ranching in eastern Amazonia. Interciencia, v. 13, p. 233-240, 1985 .

HOLTZ-EAKIN, D.; NEWEY, W.; ROSEN, H. Implementing causality tests with panel data, with an example from local public finance. 1985. (NBER Technical Paper Series, 48).

HOLTZ-EAKIN, D.; NEWEY, W.; ROSEN, H. S. Estimating vector autoregression with panel data. Econometrica, v. 56, p. 1371-1396, 1988.

HSIAO, C. Analysis of panel data. Cambridge University Press: Cambridge, 1986.

HSIAO, C. Modeling ontario regional electricity system demand using a mixed fixed and random coefficients approach. Regional Science and Urban Economics, v. 19, p. 565-587, 1989.
HURLIN, C. Testing Granger causality in heterogeneous panel data models with fixed coefficients. University Orléans, 2004a. Miméo.

HURLIN, C. A note on causality tests in panel data models with random coefficients. University Orléans, 2004b. Miméo.

HURLIN, C.; VENET, B. Granger causality tests in panel data models with fixed coefficients. University Paris IX, 2001. Miméo.

IM, K. S.; PESARAN, M. H.; SHIN, Y. Testing for unit roots in heterogeneous panels. University of Cambridge, 1997. (DAE Working Papers Amalgamated Series, 9526).

IM, K. S.; PESARAN, M. H.; SHIN, Y. Testing for unit roots in heterogeneous panels. Journal of Econometrics, v. 115 p. $53-74,2003$.

INSTITUTO BRASILEIRO DE GEOGRAFIA E ESTATÍSTICA - IBGE. Censo Agropecuário 1975. Rio de Janeiro: IBGE, 1976.

INSTITUTO BRASILEIRO DE GEOGRAFIA E ESTATÍSTICA - IBGE. Censo Agropecuário 1980. Rio de Janeiro: IBGE, 1982.

INSTITUTO BRASILEIRO DE GEOGRAFIA E ESTATÍSTICA - IBGE. Censo Agropecuário 1985. Rio de Janeiro: IBGE, 1991.

INSTITUTO BRASILEIRO DE GEOGRAFIA E ESTATÍSTICA - IBGE. Censo Agropecuário 1995/1996. Rio de Janeiro: IBGE, 1998. 
KAIMOWITZ, D; MERTENS, B; WUNDER, S AND PACHECO, P. Hamburger connection files Amazon destruction. Bangon, Indonesia: Center for International Forest Research, 2004.

KIVIET, J. F.; PHILLIPS, G. D. A. Alternative bias approximation in regressions with a lagged dependent variable.

Econometric Theory, v. 9, p. $62-80,1993$.

KIVIET, J. F.; PHILLIPS, G. D. A. Bias assessment and reduction in linear error-correction models. Journal of Econometrics, v. 63, p. 215-243, 1994.

LEVIN, A.; LIN, C. F.; Chu, C. Unit root tests in panel data: asymptotic and finite-sample properties. Journal of Econometrics, v. 108, p. 1-24, 2002.

MADDALA, G. S. The use of variance components models in pooling cross-section and time series Data. Econometrica, n. 39, p. 341-358, 1971.

MAHAR, D. J. Deforestation in Brazil's Amazon region: magnitude, rate and causes. New York: The World Bank, 1988.

MARGULIUS, Sérgio. Causas do desmatamento da Amazônia brasileira. Brasília: Banco Mundial, 2004.

MARINHO, E.; LINHARES, F.; CAMPELO, G. Os programas de transferencias de renda do governo impactam a pobreza no Brasil? Laboratório de Estudo da Pobreza, CAEN-UFC, 2007.
MERTENS, B.; POCCARDCHAPUIS, R.; PIKETTY, M. G.; LACQUES, A. E. VENTURIERI, A. Crosssing spatial analyses and livestock economics to understand deforestation process in Brazilian Amazon: the case of São Felix do Xingu in South Pará. Agricultural Economics, n. 27, p. 269-294, 2002.

\section{MINISTÉRIO DA}

INTEGRAÇ̃̃O

NACIONAL/MINISTÉRIO DO

MEIO AMBIENTE. Plano

Amazônia Sustentável - PAS.

Diagnóstico e Estratégia, v. 1,

Brasília, 2004.

NAIR-REICHERT, U.; WEINHOLD, D. Causality tests for cross-country panels: a new look at FDI and economic growth in developing countries. Oxford Bulletin of Economics and Statistics, v. 63, p. 153-171, 2001.

NANKERVIS, J. S.; SAVIN, N. E. Finite sample distributions of $t$ and $F$ statistics in an AR(1) model with an exogenous variable.

Econometric Theory, v. 3 p. 387-408, 1987.

NEPSTAD Daniel $e$ t. al. Road paving, fire regime feedbacks, and the future of Amazon forests. Forest Ecology and Management, n. 154 , p. 395-497, 2001

NEPSTAD, D.; CAPOBIANCO, A. C. B.; CARVALHO, G.; MOUTINHO, P.; LOPES, U; LEFEBVRE, P. Avanca Brasil: os custos ambientais para a

Amazônia. Belém: Alves, 2000.
NEPSTAD, D. C.; STICKLER, C.; ALMEIDA, O. T.

Globalization on the Amazon soy and beef industries: opportunities for conservation. Conservation Biology, v. 20, p. 1595-1603, 2006.

NEPSTAD, Daniel; STICKLER, Claudia; ALMEIDA, O. T. Managing the tropical agriculture revolution. Journal of Sustainable Forestry, 2008.

NERVOLE, M. Further Evidence on the Estimation of dynamic economic relations from a Time Series of Cross-Sections,

Econometrica, v. 39, p. $359-387,1971$

NICKELL, S. Biases in dynamics models with fixed effects. Econometrica, v. 49, p. 1399-1416, 1981.

OLIVEIRA, Ariovaldo Umbelino de Oliveira. BR-163

Cuiabá-Santarém: geopolítica, grilagem, violência e mundialização. In: TORES, Maurício (Org.). Amazônia revelada: os descaminhos ao longo da BR-163. Brasília: CNPq, 2005.

PARKES, Ariel; GRILICHES, Zvi. Estimating distributed lags in short panels with an application to the specification of depreciation patterns and capital stock constructs. Review of Economic Studies, v. 51, p. 243-262, 1984.
PIKETTY, M-G.; VEIGA, J. B.; TOURRAND, J-F.; ALVES, A. M.; POCCARD-CHAPUIS, R.; THALES, M. C.; HOUSTIOU, N.; VENTURIERI A. Por que a pecuária está avançando na

Amazônia Oriental? In: SAYAGO, D.; TOURRAND, J-F.; BURZSTYN, M. (Org.). Amazônia; cenas e cenários. Brasília: Universidade de Brasília, 2004.

PUTY, C.; ALMEIDA, O. T.; RIVERO, S. L. M. A produção mecanizada de grãos e seu impacto no desmatamento amazônico. Ciência Hoje, v. 40, p. 44-48, 2007.

REARDON, Thomas; VOSTI, Stephen A. Links between rural poverty and environment in developing countries: asset cetegories and investment poverty. World Development, v. 23, n. 9, p. 1495-1506, 1995.

REIS, E.; MARGULLIS, $\mathrm{S}$. Options for slowing Amazon jungle clearing. In:

DORNBUSCH, R.; POTERBA, J. (Ed.). Economic policy responses to global warming. Cambridge: MIT Press, 1991.

RIVAS, A. A. F.; MOTA, J. A.; MACHADO, J. A. Impacto virtuoso do Polo Industrial de Manaus sobre a proteção da floresta amazônica: discurso ou fato? Manaus-AM: Instituto Piatam, 2008. (Resumo executivo). 
RODRIGUES, Ricardo Leonardo Vianna. Causas do desmatamento da Amazônia brasileira. Tese (Doutorado) - COPPE/UFRJ, Rio de Janeiro, 2004.

SERRÃO E. A. S.; TOLEDO J.

M. The search for sustainability in Amazonian pastures. In: ANDERSON, A. B. (Ed.). Alternatives to deforestation: steps towards sustainable utilization of Amazon forest. New York: Columbia University Press, 1990. p. 195-214.

TEJADA, C. A. O.; JACINTO, P. A.; SANTOS, A. M. A.; SOUSA, E. A. Saúde e pobreza no Brasil: uma análise de causalidade de Granger com dados em painel. In: Encontro Nacional de Economia Regional, 5., 2007, Recife. Anais... Recife : Editora da UFPE, 2007.

WALKER, R. T. Land use transition and deforestation in developing countries. Geographical Analysis, v. 19, n. 1, p. 18-30, 1987.

WEHRMANN, M. E. S. de F.; DUARTE, L. M. G. O que há em comum entre a Região das Missões e Lavrados de Roraima ou os percursos da soja até a Amazônia Legal. In: SAYAGO, D.; TOURRAND, J-F.; BURZSTYN, M. (Org.). Amazônia; cenas e cenários. Brasília: Universidade de Brasília, 2004.

WEINHOLD, D. Investment, growth and causality testing in panels. Economie et Prevision, v. 126, p. 163-175, 1996.
WEINHOLD, D. A dynamic 'fixed effects' model for heterogeneous panel data. London School of

Economics, 1999.

(unpublished manuscript).

WEINHOLD, D.; REIS E. Model avaluation and causality testing in short panels; the case of infrastructure provision and population growth in the Brasilian Amazon, (1975-1985), 2001.

WOOD, C.; SCHMINK; M.

Contested frontiers in Amazonia.

New York: Columbia University

Press, 1992.

WOOLDRIDGE, Jeffrey M.

Econometric analysis of cross-section and panel data. Cambridge,

Massachusetts: The MIT

Press, 2002.

WOOLDRIDGE, Jeffrey M. Introductory econometrics: a modern approach-2E. Maison, Ohio:

Thomson South -

Western, 2003.

WUNDER, Sven. Poverty alleviation and tropical forests - What scope for synergies? World Development, v. 29, n. 11, p. 1817-2001, 2001.

YOUNG, C. Public Policies and Deforestation in the Brazilian Amazon. Planejamento e Políticas Públicas, n. 18, Rio de janeiro, IPEA, p. 201-222, 1998

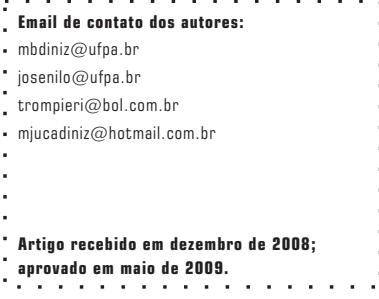

